\title{
PENDEKATAN MULTI DIMENSIONAL SCALING UNTUK EVALUASI KEBERLANJUTAN WADUK CIRATA - PROPINSI JAWA BARAT (Multidimensional Scaling Approach to Evaluate Sustainability of Cirata Reservoir - West Java Province)
}

\author{
Kholil $^{1^{*}}$, Tony Atyanto Dharoko ${ }^{2}$ dan Ani Widayati ${ }^{3}$ \\ ${ }^{1}$ Jurusan Teknik Lingkungan Universitas Sahid Jakarta, \\ Jln. Prof. Supomo No 84 Jakarta Selatan 12870. \\ ${ }^{2}$ Jurusan Teknik Asitektur, Universitas Gajah Mada, \\ Jln. Grafika, Yogyakarta 55281. \\ ${ }^{3}$ Pusat Penelitian Perikanan Budidaya Air Tawar, Kementerian Kelautan dan Perikanan, \\ Jln. Sempur No.1 Bogor. \\ *Penulis korespondensi. No Tel : 021 8312815. Email: kholil2005@yahoo.com.
}

Diterima: 15 Juli 2014

Disetujui: 8 Desember 2014

\begin{abstract}
Abstrak
Waduk Cirata merupakan salah satu waduk di Indonesia yang memiliki peran sangat besar bagi pembangunan ekonomi, sebagai Pembangkit Listrik Tenaga Air (PLTA). Pertumbuhan Keramba Jaring Apung (KJA) dan perkembangan permukiman di sekitar waduk, serta perubahan tataruang di DAS Citarum untuk kegiatan permukiman, industri, pertanian, dan peternakan menyebabkan peningkatan sedimentasi dan penurunan kualitas air waduk, sehingga berpengaruh terhadap kinerja dan keberlajutan waduk. Kajian ini bertujuan untuk mengetahui tingkat keberlanjutan waduk dengan menggunakan metode Multidimesional Scaling berdasarkan 5 dimensi yaitu ekologi dan tata ruang, ekonomi, sosial dan budaya, peraturan dan kelembagaan, dan infrastruktur dan teknologi. Hasil analisis MDS menunjukkan bahwa dimensi ekologi dan tataruang, dan peraturan dan kelembagaan kurang berlanjut dengan nilai indeks keberlanjutan masing-masing 45,76 dan 42,24. Sementara untuk dimensi ekonomi, sosial dan budaya, dan infrastruktur dan teknologi memiliki nilai indeks keberlanjutan masing-masing 63,12; 64,42 dan 68,64 yang berarti hanya masuk kategori cukup berlanjut. Atribut yang paling sensitif yang mempengaruhi indeks keberlanjutan ekologi dan tataruang adalah laju sedimentasi, jumlah KJA dan kualitas air waduk. Pada dimensi peraturan dan kelembagaan adalah lemahnya koordinasi, perijinan dan penegakan hukum. Untuk menjamin keberlanjutan kinerja Waduk Cirata perlu dilakukan pengendalian penggunaan lahan di DAS Citarum dan permukiman di sekitar waduk, pengetatan perijinan, dan penegakan hukum.
\end{abstract}

Kata kunci: indeks keberlanjutan, kualitas air, pembangunan berkeberlanjutan, tata ruang, waduk.

\begin{abstract}
Cirata reservoir is one of the reservoirs in Indonesia, that plays an important role for economic development as a Hydroelectric Power Plant. The development of settlement around the dam, and land use change of Citarum's watershed for industrial activities, agriculture, and animal husbandry have increased the erosion, sedimentation and degradation water quality of reservoir. This paper will discuss the level of sustainability of the reservoir using Multidimesional Scaling (MDS) based on five dimensions: ecology and spatial, economics, social and culture, regulations and institutional, and infrastructure and technology. MDS analysis results showed that the dimension of ecological and spatial, institutional and the regulation are lack of sustainability due to the low index score of 45.76 and 42.24. While for economic, social and culture, and infrastructure and technology dimension score is 6312; 64,42 and 68,64 (only the sufficient sustainability). The most sensitive atributes that influence to sustainability index of ecological and spatial dimension are sedimentation rate, the amount of KJA, and water quality of reservoir. To ensure sustainability of cirata reservoir required to control land use change in upstream Citarum Watershed and settlement around the reservoir, tightening of licensing and law enforcement.
\end{abstract}

Keywords: reservoir, spatial, sustainable development, sustainability index, water quality.

\section{PENDAHULUAN}

Waduk Cirata memiliki fungsi yang sangat besar bagi pengembangan ekonomi khususnya daerah sekitar dan daerah di hilirnya (Karawang, Bekasi dan Jakarta). Waduk ini dibangun di DAS
Citarum, yang luasnya 6.200 hektar (ha) dengan luas tangkapan air 603.200 ha. Wilayah genangan airnya meliputi Kabupaten Cianjur, Purwakarta dan Bandung Barat. Kedalaman rata-rata $34,9 \mathrm{~m}$, dengan daya tampung air mencapai 2.165.000.000 $\mathrm{m}^{3}$. Fungsi utamanya adalah sebagai Pembangkit 
Listrik Tenaga Air (PLTA) dengan kapasitas 1008 MW untuk wilayah Jawa Bali (Anonim, 2012 memperkirakan dengan produksi listrik sebesar itu, diperkirakan mampu menghemat BBM sebesar Rp 2,8 trilyun/tahun.

Di samping fungsi utama tersebut, juga memiliki fungsi lainnya sebagai pengendali tata air, penyedia air untuk irigasi pertanian dan industri, serta sebagai sumber air baku untuk penyediaan air minum bagi masyarakat Jakarta. Sejak pertama diresmikan tahun 1988 waduk ini telah menjadi tempat mencari nafkah bagi sebagian besar masyarakat yang tinggal di sekitar waduk melalui kegiatan budidaya ikan dengan sistem Keramba Jaring Apung (KJA). Pada saat waduk Cirata diresmikan jumlah KJA yang diijinkan hanya 12,000 (1 \%) dari luas permukaan. Namun perkembangan KJA terus meningkat dengan sangat pesat, rata-rata peningkatan per tahun mencapai 14\%, pada tahun 2012 (setelah 24 tahun sejak diresmikan) jumlah KJA telah mencapai sekitar 53 ribu. Ini berarti sudah mencapai hampir 5 kali dari rencana yang dibuat (Anonim, 2012 ${ }^{\mathrm{b}}$ ).

Potensi ekonomi dari kegiatan KJA sangat besar, dengan jumlah KJA sekitar 53 ribu, dan melibatkan sekitar 25000 tenaga kerja yang menggantungkan hidupnya sebagai tempat mencari nafkah, perputaran uang di Waduk Cirata mencapai Rp 2,8 trilyun/tahun untuk gaji pekerja, pakan ikan dan nilai produksi ikan yang mencapai 6500- 7000 ton/tahun, produksi ini mencapai $39.5 \%$ dari total produksi ikan di Jawa Barat (Anonim, 2012 ${ }^{\mathrm{b}}$ ).

Sumber utama air Waduk Cirata adalah Sungai Citarum dan anak Sungai Citarum seperti sungaisungai Cisokan, Cikundul, Cibalagung dan Cimeta yang bersumber dari mata air di Gunung Wayang. Sungai ini mengalir sepanjang sekitar $300 \mathrm{~km}$ dari hulu sampai hilir melewati permukiman penduduk, kawasan pertanian, industri dan peternakan. Dalam 10 tahun terahir ini, telah terjadi perkembangan yang sangat pesat di kawasan Daerah Aliran Sungai (DAS) Citarum, terutama pertumbuhan permukiman penduduk akibat pertambahan penduduk, dan aktivitas industri, pertanian serta peternakan. Perkembangan permukiman, peternakan dan industri di DAS Citarum telah menambah kawasan kedap air (impervious area) dengan tingkat pertambahan sekitar 10-14\%/tahun, selain itu juga meningkatkan erosi tanah yang terbawa ke waduk melalui aliran Sungai Citarum dan anak Sungai Citarum (Anonim, 2011). Mawardi (2010) menyatakan bahwa aktivitas penduduk dan perubahan tataguna lahan di beberapa hulu DAS di Pulau Jawa seperti Bengawan Solo, Brantas, Citarum dan Ciliwung telah menjadi penyebab meningkatnya erosi dan sedimentasi. Li dan Liu (2014) juga menyatakan bahwa perubahan tataguna lahan di hulu DAS Xijiang Cina telah menjadi sebab utama meningkatnya erosi tanah ketika musim hujan.

Peran penting Waduk Cirata bagi pembangunan ekonomi khususnya di propinsi Jawa Barat diharapkan tidak hanya pada masa kini, tetapi berlanjut untuk masa yang lebih lama. Berdasarkan rancangan yang dibuat pada tahun 1987, waduk ini diharapkan mampu bertahan sampai 100 tahun. Namun menurunna kualitas air waduk akibat pencemaran dan laju sedimentasi akibat erosi melalui Sungai Citarum serta tekanan penduduk sekitar waduk bisa mengurangi usia waduk, hanya menjadi 60 tahun (Anonim, 2013 ${ }^{\mathrm{a}}$ ). Berdasarkan kondisi obyektif waduk saat ini, maka kinerja waduk untuk kepentingan ekonomi, sosial dan lingkungan secara keseluruhan tidak dapat dipisahkan degan aktivitas penduduk dan pemanfaatan tata ruang secara menyeluruh di kawasan sekitar waduk dan hulu DAS Citarum yang menjadi inlet utama waduk.

Sesuai dengan UU No 26 tahun 2008, tentang Rencana Tata Ruang Wilayah Nasional pasal 51, Waduk Cirata termasuk kawasan lindung yang harus dilindungi. Dalam Undang-Undang No 26 tahun 2007, tentang penataan ruang, pasal 1, ayat 21 kawasan lindung adalah kawasan yang memiliki fungsi untuk melindungi kelestarian lingkungan hidup sumberdaya alam dan sumber daya buatan. Indikator keberlajutan pemanfaatan Waduk Cirata, dapat mengadopsi konsep pembangunan berkelanjutan yang tidak hanya menekankan pada aspek ekonomi, tetapi sosial dan ekologi (Khanna dkk., 1999; dan Dahuri, 2004). Inti dari konsep ini adalah bahwa tujuan sosial, ekonomi, dan lingkungan harus saling mendukung dan terkait dalam proses pembangunan. Bila tidak akan terjadi "trade off" antar tujuan (Munasinghe, 1993). Masyarakat sekitar harus dilibatkan dalam pengelolaan sumberdaya alam untuk menjamin keberlanjutan pemanfaatannya (Moffat dkk., 2001). Keberlanjutan jangka panjang sangat ditentukan oleh ketersediaan sumberdaya alam (Khanna dkk., 1999). Moffat dkk (2001) dan The United Nation Commision on Sustainable Development (Anonim, 2011) menambahkan 1 pilar lagi yakni etika, sebagai pilar ke 4. Sementara Orice dan Messerli (2002) dalam Fauzi dan Anna (2007) memasukkan budaya dan gender (culture and gender), dan kebijakan dan legislasi sebagai pilar ke 5 . Operasionalisasi pembangunan berkelanjutan dilakukan melalui konsep daya dukung (carrying capacity) (Wackkernagel, 1994; Rees, 1996; Khanna dkk., 1999). Operasionalisasi daya dukung lingkungan meliputi 3 hal yaitu perkiraan kapasitas pendukung, perkiraan kapasitas asimilasi, dan alokasi optimal sumber daya. Perkiraan kapasitas 
pendukung (Rees, 1996 dan Khanna dkk., 1999) terdiri atas regenerasi, ketahanan dan titik kritis. Perkiraan kapasitas asimilasi adalah perkiraan kemampuan ekosistem menyerap suatu limbah atau beban pencemar yang masuk tanpa menimbulkan dampak ekosistem.

Daya dukung lingkungan dapat meliputi daya dukung lingkungan untuk biologi dan daya dukung lingkungan untuk penduduk (Khanna dkk., 1999). Daya dukung lingkungan biologi adalah tingkat konsumsi sumber daya dan pembuangan limbah maksimum yang masih dapat dipertahankan tanpa batas waktu dan secara progresif tidak mengganggu bio produktivitas dan integritas ekologi suatu kawasan. Untuk daya dukung lingkungan untuk penduduk adalah kemampuan lingkungan untuk mendukung kehidupan manusia berkelanjutan. Indikator daya dukung dapat dilihat dari jumlah penduduknya, Meadow dkk (2004) menyatakan jika kepadatan penduduk kurang dari 50 orang/ha dikategorikan berkelanjutan, 100-150 kritis dan lebih dari 200 tidak berlanjut. Cara kedua bisa menggunakan ecological foot print, yakni berapa jumlah lahan yang dibutuhkan per kapita untuk menghasilkan secara ekslusif barang dan jasa, termasuk memenuhi kebutuhan makan, energi, air dan lainnya dan menghasilkan limbah tanpa perlu pengolahan (Wackernagel, 1994).

Permasalahan yang muncul di Waduk Cirata saat ini adalah laju sedimentasi akibat erosi yang masuk dari Sungai Citarum, pengendapan sisa pakan KJA, dan penurunan kualitas air akibat limbah domestik. Limbah ini berasal dari permukiman di sekitar DAS Citarum dan permukiman sekitar waduk, limbah industri, kegiatan pertanian dan peternakan di hulu DAS Citarum. Laju rata-rata sedimentasi telah mencapai 7,3 juta $\mathrm{m}^{3} /$ tahun, jauh di atas rancangan yang dibuat yakni 5,67 juta $\mathrm{m}^{3} /$ tahun (Anonim, 2012 ). Erosi dan limbah yang masuk melalui Sungai Citarum dan anak sungainya disebabkan oleh pertumbuhan penduduk dan permukiman yang sangat pesat, aktivitas industri, peternakan serta pertanian di DAS Citarum, yang ditandai dengan alih fungsi lahan yang tidak sesuai dengan tata ruang (Respati dan Dian, 2013). Untuk kualitas air waduk berdasarkan hasil pemantauan (Anonim, $2013^{\mathrm{a}}$ ) terhadap para meter BOD, COD, DO dan $\mathrm{H}_{2} \mathrm{~S}$ dengan menggunakan metode Storet berada pada kategori buruk-sedang. Penurunan kualitas air waduk akan menjadi penyebab terjadinya upwelling, yaitu peristiwa terjadinya pembalikan air dari dasar waduk yang sangat toksik ke permukaan, sehingga mengakibatkan kematian ikan secara masal (Anonim, 2012 ${ }^{\mathrm{b}}$ ). Dewa dan Pratista (2010) menyatakan bahwa penurunan suhu air juga dapat menjadi penyebab terjadinya upwelling. Penurunan kualitas air waduk akibat pencemaran yang disebabkan sisa pakan ikan dari KJA, limbah rumah tangga dan limbah industri dapat mengganggu kerja turbin pada Pembangkit Listrik Tenaga Air (PLTA) karena korosif (Anonim, 2013 ${ }^{\mathrm{b}}$ ). Faktor lain yang mempengaruhi kerja turbin adalah volume air waduk, peningkatan sedimentasi akan menurunkan volume air dan berdampak pada kinerja turbin (Anonim, 2012 ; Kemal dan Prajitno 2013). Bila kondisi ini dibiarkan terus, jelas akan mempengaruhi kinerja waduk. Oleh karena itu perlu dilakukan evaluasi untuk mengetahui tingkat keberlajutan waduk agar dapat menentukan langkah yang tepat untuk menjamin keberlanjutan kinerja waduk.

Berdasarkan permasalahan tersebut, maka kajian ini bertujuan untuk mengetahui tingkat keberlanjutan waduk, berdasarkan 5 dimensi yaitu ekologi dan tata ruang, ekonomi, sosial dan budaya, peraturan dan kelembagaan, serta infrastruktur dan teknologi. Keterkaitan tata ruang dengan kinerja Waduk Cirata menjadi aspek yang penting untuk dievaluasi mengingat keberlanjutan waduk sangat dipengaruhi oleh perkembangan tata ruang baik di hulu maupun di sekitar waduk itu sendiri.

\section{METODE PENELITIAN}

\section{Waktu dan Lokasi}

Penelitian dilakukan di Waduk Cirata yang secara administratif berada di tiga kabupaten yaitu Cianjur, Bandung Barat dan Purwakarta, Jawa Barat. Penelitian dilakukan selama enam bulan (Mei-Oktober 2013). Pengambilan data primer dilakukan secara langsung di lapangan, melalui pengamatan dan diskusi dengan para petani KJA dan pimpinan kelompok KJA di Waduk Cirata, serta diskusi dengan beberapa pakar terkait (pengelola waduk, akademisi, birokrat dan pelaku usaha perikanan). Di samping itu juga penelusuran data sekunder dari berbagai sumber resmi seperti BPWC, Pembangkit Jawa Bali (BPJ), Unit Pelaksana Teknis (UPT) Waduk Cirata, Pemda Cianjur, Purwakarta dan Bandung Barat.

\section{Prosedur}

Analisis data menggunakan Multidimensional Scalling (MDS). Kruskal (1977); Borg dan Groenen (2005) menyatakan bahwa MDS merupakan analisis statistik untuk mengetahui kemiripan dan ketidak miripan variabel yang digambarkan dalam ruang geometris. Kelemahannya menurut Lee (2011) adalah hanya berdasarkan pada permodelan kognitif.

Ada beberapa langkah yang dilakukan dalam penggunaan MDS, yaitu penentuan dimensi dan atribut melalui diskusi pakar, penilaian dan 
pemberian skor secara ordinal dalam rentang 0 (buruk) sampai 3 (baik) sesuai dengan karakter atribut oleh responden terpilih atau berdasarkan data-data yang didapat (baik primer maupun sekunder). Langkah selanjutnya melakukan ordinansi MDS terhadap dimensi analisis pengungkit (leverage factor) dari atribut-atribut berdasarkan Root Mean Square (RMS) pada sumbu x. Tahap akhir adalah melakukan analisis Monte Carlo untuk mengetahui pengaruh galat dalam pemberian skor.

Untuk mengetahui ketepatan analisis dilakukan penentuan Goodness of fit dalam MDS berdasarkan nilai S-Stress yang dihitung dari nilai S dan $\mathrm{R}^{2}$. Proses iterasi dapat dihentikan jika nilai $\mathrm{R}^{2}$ sudah mendekati 1 . Nilai stress yang rendah menunjukkan good fit dan nilai $\mathrm{S}$ yang tinggi menunjukkan sebaliknya. Penghitungan indek keberlanjutan menggunakan bantuan perangkat lunak Rapfish (Rapid Appraisal for Fisheries) yang dikembangkan oleh Rapfish Group Fisheries Centre University of British Columbia, Kanada (Pitcher, 1999; Fauzy dan Anna, 2005). Metode MDS ini dipilih karena mampu memberikan hasil secara menyeluruh, cepat dan obyektif terkait dengan aspek-aspek yang mempengaruhi keberlanjutan waduk, sehingga memudahkan untuk mengimplementasikan dalam kebijakan. Metode ini telah banyak digunakan untuk mengidentifikasi tingkat keberlanjutan pengelolaan sumberdaya alam. Penelitian Kholil dan Dewi, (2014) telah dapat mengidentifikasi tingkat keberlanjutan pengelolaan sumberdaya perikanan di Kepulauan Seribu dengan menggunakan MDS, demikian juga Nurmalina (2008) dengan menggunakan MDS dapat mengidentifikasi tingkat keberlanjutan ekologi, ekonomi dan sosial terhadap ketersediaan beras di Jawa dan luar Jawa (Kalimantan dan Sumatra). Secara umum tahapan dan metode evaluasi keberlanjutan Waduk Cirata menggunakan MSD seperti Gambar 1.

Nilai indeks keberlanjutan menggunakan skala yang dikembangkan University Columbia, Canada dalam Fauzi dan Anna (2005), disajikan pada Tabel 1.

\section{HASIL DAN PEMBAHASAN}

Berdasarkan hasil penilaian atribut oleh responden yang mewakili Dinas Perikanan Cianjur, UPT Waduk Cirata, BPWC, PJB dan kelompok Petani KJA serta berdasarkan penelaahan data-data sekunder yang telah dikumpulkan, hasil analisis MDS dengan menggunakan Rapfish.

\section{Nilai Indeks Keberlanjutan Dimensi Ekologi dan Tataruang}

Nilai indeks keberlanjutan berdasarkan hasil analisis MDS pada dimensi ekologi dan tata ruang adalah 45,76, berada pada skor buruk dan baik, tetapi lebih dekat ke buruk (kurang berlanjut), seperti Gambar 2.

Beberapa atribut yang sensitif dan mempengaruhi dimensi ini berdasarkan hasil analisis leverage factor terhadap 10 atribut yang dilihat dari nilai Root Mean Square (RMS), menunjukkan 3 atribut yang sangat sensitif, yaitu laju sedimentasi $(3,16)$, jumlah KJA $(2,97)$ dan kualitas air waduk (2,97), seperti pada Gambar 3.

Tabel 1. Kategori status keberlanjutan.

\begin{tabular}{cc}
\hline Nilai indeks & Kategori \\
\hline $0,00-25,00$ & Buruk (tidak berkelanjutan) \\
$25,01-50,00$ & Kurang (kurang berkelanjutan) \\
$50,01-75,00$ & Cukup (cukup berkelanjutan) \\
$75,01-100,00$ & Baik (sangat berkelanjutan) \\
\hline
\end{tabular}

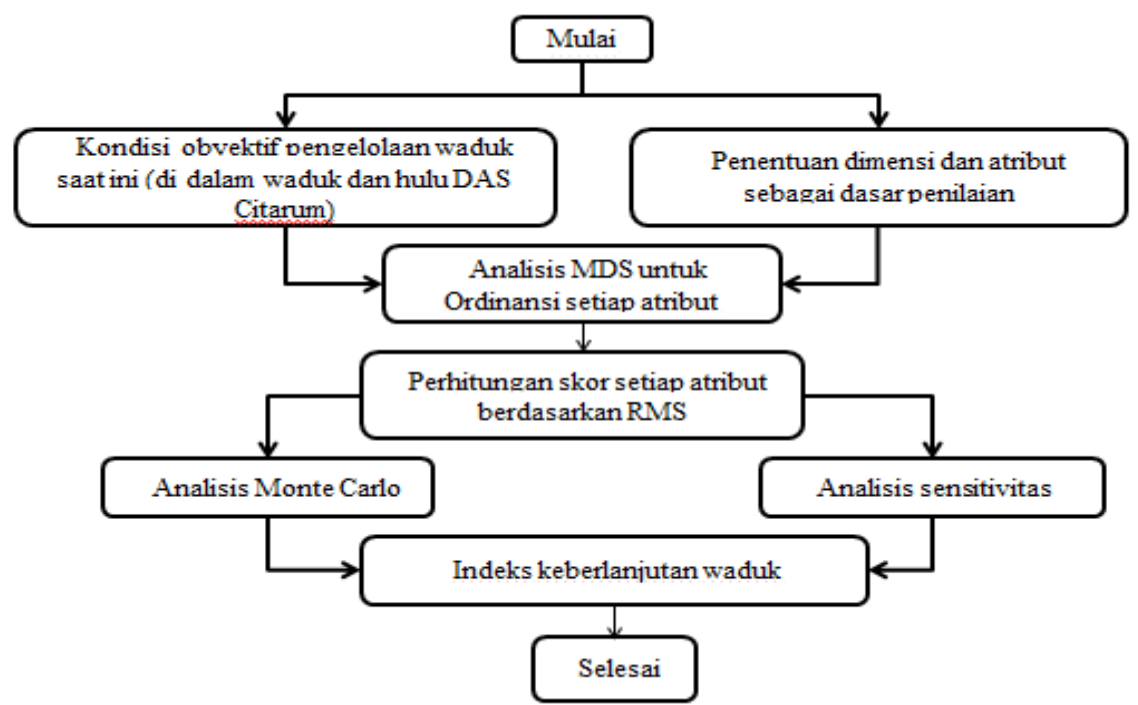

Gambar 1. Tahapan dan metoda evaluasi keberlanjutan Waduk Cirata menggunakan MDS. 


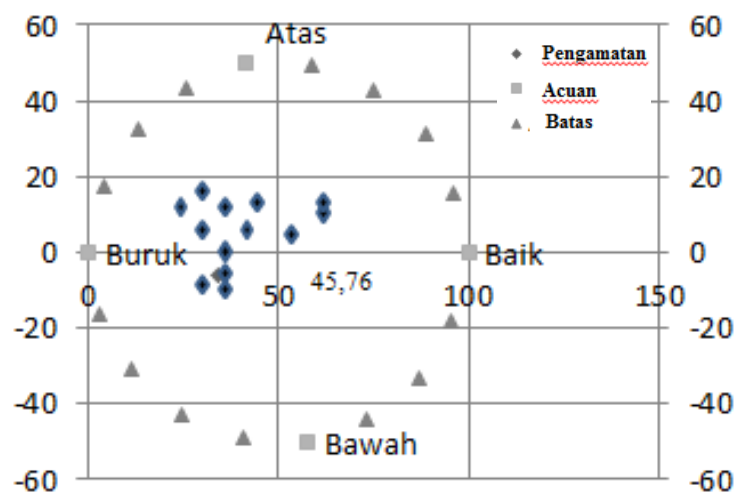

Gambar 2. Indek keberlanjutan dimensi ekologi dan tata ruang.

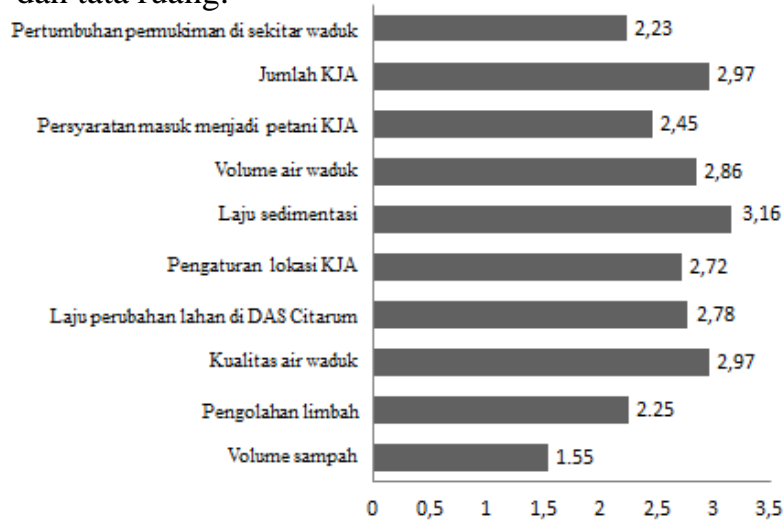

Gambar 3. Peran masing-masing atribut dimensi ekologi dan tata ruang yang dinyatakan dalam bentuk perubahan RMS.

Hasil analisis pada Gambar 3 menunjukkan bahwa atribut yang paling sensitif berdasarkan nilai RMS adalah laju sedimentasi $(3,16)$, kualitas air waduk $(2,97)$ dan pembatasan jumlah KJA $(2,97)$. Hal ini memiliki makna bahwa untuk meningkatkan nilai keberlanjutan pada dimensi ekologi dan tata ruang harus ada intervensi kebijakan khusus untuk pengendalian sedimentasi, menurunkan pencemaran air waduk dan pembatasan KJA. Beberapa intervensi kebijakan tersebut antara lain : untuk pengendalian sedimentasi akibat erosi dari DAS Citarum, pemerintah daerah khususnya yang dilewati DAS Citarum yakni Pemda Bandung Barat harus melakukan normalisasi DAS Citarum dengan penanaman kembali di sekitar DAS, membatasi perubahan tataguna lahan yang tidak sesuai, dan merelokasi permukiman di sekitar DAS pada jarak 100 meter sesuai PP No 26 tahun 2008, dan UU No 26 tahun 2007. Demikian juga pemda daerah dan BPWC harus merelokasi permukiman di sekitar waduk dengan melibatkan tokoh masyarakat. Untuk mengendalikan sedimentasi akibat KJA, BPWC harus membatasi KJA dengan memperketat perijinan, penataan KJA, dan pengembangan zonasi khusus untuk KJA. Untuk menjaga kualitas air waduk, seluruh industri dan peternakan yang berada

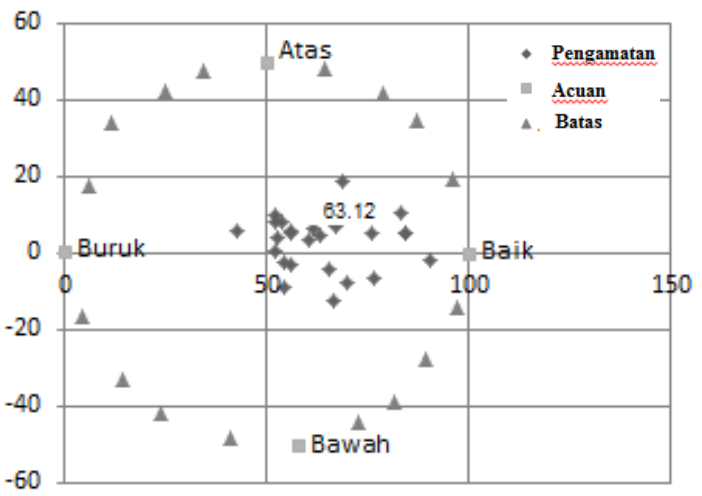

Gambar 4. Indek keberlanjutan dimensi ekonomi

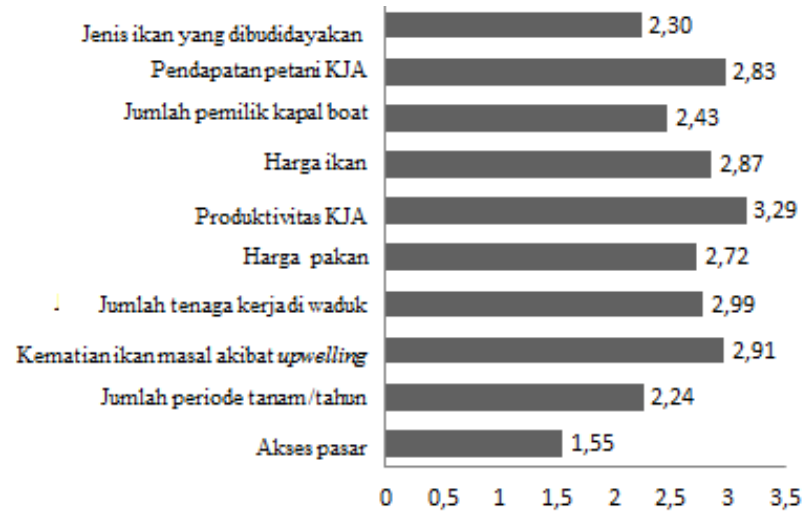

Gambar 5. Peran masing-masing atribut dimensi ekonomi yang dinyatakan dalam bentuk perubahan RMS.

di DAS Citarum harus membangun pengolahan limbah di sumbernya, demikian juga permukiman di sepanjang DAS Citarum dan di sekitar waduk harus melakukan pengolahan sampah di sumber. Kebijakan terakhir adalah penegakan hukum terhadap pelanggar baik di hulu DAS Ciliwung maupun di sekitar waduk dengan melibatkan parat keamanan atau penegak hukum.

\section{Nilai Indeks Keberlanjutan Dimensi Ekonomi}

Hasil ordonansi MDS untuk dimensi ekonomi, menunjukkan bahwa nilai indek keberlanjutannya 63,12. Berdasarkan skala keberlanjutan masuk dalam kategori cukup berlanjut, seperti pada Gambar 4.

Kategori cukup ini menunjukkan bahwa kondisi eksisting waduk saat ini menanggung beban berat terutama sedimentasi dan pencemaran kualitas air waduk, yang secara akumulatif telah mengganggu kinerja waduk dari segi ekonomia yang ditandai dengan penurunan produktivitas KJA dan kinerja utamanya sebagai PLTA. Produktivitas KJA saat ini hanya tingga 50-60 \%, dan kerja turbin PLA sudah mulai menurun akibat korosi (Anonim, 2012). 
Dari 10 atribut pada dimensi ekonomi, berdasarkan nilai RMS hasil analisis leverage factor, menunjukkan bahwa atribut produktivitas KJA memiliki nilai tertinggi $(3,29)$, diikuti jumlah tenaga kerja di dalam waduk $(2,99)$ dan kematian ikan secara masal akibat upwelling (2,91), sebagaimana pada Gambar 5.

Hal ini menunjukkan bahwa untuk meningkatkan keberlanjutan pada dimensi ekonomi maka produktivitas ikan /KJA harus ditingkatkan. Mengingat penurunan produktivitas KJA akan menurunkan pendapatan petani KJA, dengan sendirinya akan banyak KJA yang ditutup. Penurunan produktivitas KJA dapat terjadi karena pencemaran air waduk, atau kematian ikan secara masal akibat upwelling, yang secara langsung juga akan menurunkan pendapatan petani. Upaya peningkatkan produktivitas KJA dapat dilakukan melalui beberapa kegiatan sosialisasi secara door to door kepada petani KJA tentang sistem budidaya ikan melalui KJA yang benar dan efisien misalnya dengan mengembangan KJA ganda untuk budidaya ikan gurame dan ikan nila, langkah-langkah antisipasi menghadapi upwelling untuk menghindari kematian ikan masal yang merugikan petani KJA, dan mengembangkan pakan ikan secara mandiri untuk mengurangi biaya pakan yang mencapai $60 \%$ dari biaya produksi.

\section{Nilai Indeks Keberlanjutan Dimensi Sosial dan Budaya}

Hasil ordonansi MDS pada dimensi sosial dan budaya, menunjukkan bahwa nilai indek keberlanjutannya 64,42. Berdasarkan kriteria indek keberlanjutan masuk kategori cukup berlanjut (Gambar 6).

Ada beberapa hal yang menyebabkan nilai indek keberlanjutan dimensi sosial dan budaya tidak maksimal. Hasil analisis leverage factor terhadap 11 atribut pada dimensi sosial budaya berdasarkan nilai RMS-nya (Gambar 7) menunjukkan 3 atribut yang paling sensitif dalam dimensi sosial dan budaya, yaitu sikap tolong menolong di antara petani KJA (2,72), tingkat pendidikan formal petani KJA $(2,64)$, dan kegiatan sosisal dan keagamaan $(1,73)$.

Tolong menolong sesama petani KJA menjadi sangat penting mengingat kegiatan para petani KJA di dalam waduk terpisah dengan daratan, komunikasi dan interaksi antara mereka tidak seintensif seperti yang di darat, sehingga sangat perlu kebersamaan dan tolong-menolong, terutama dalam menghadapi gangguan seperti pencurian ikan, upwelling dan lainnya. Sementara pendidikan formal akan sangat menentukan pengetahuan mereka dalam merespon berbagai permasalahan yang sehari-hari dihadapi seperti teknik budidaya,

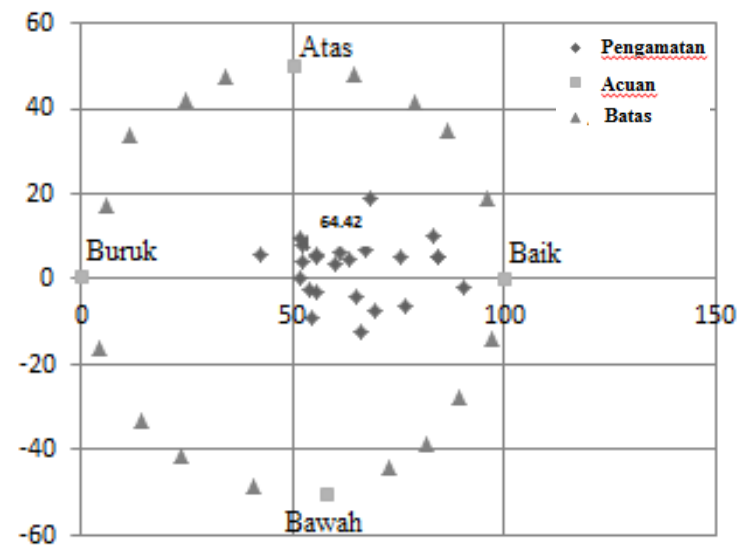

Gambar 6. Indeks keberlanjutan dimensi sosial budaya.

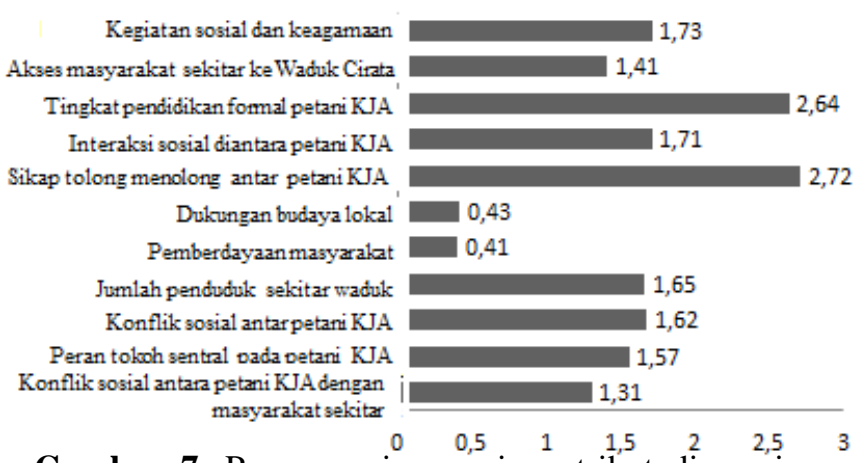

Gambar 7. Peran masing-masing atribut dimensi sosial dan budaya yang dinyatakan dalam bentuk perubahan RMS.

keterbukaan wawasan dan mekanisme penyelesaian konflik antar petani. Kegiatan sosial keagamaan akan dapat meningkatkan solidaritas dan sikap saling tolong menolong. Tiga atribut ini yang harus diperhatikan untuk meningkatkan nilai keberlajutan dimensisosial budaya. UPT Waduk Cirata perlu memfasilitas kegiatan bersama atau pertemuan rutin antar kelompok dan antar petani KJA di dalam kelompok, dan melakukan capacity development melalui penyuluhan di setiap kelompok tentang pentingnya kerjasama kelompok, manajemen, pengelolaan KJA dan lainnya.

\section{Nilai Indeks Keberlanjutan Dimensi Peraturan dan Kelembagaan}

Nilai indeks keberlanjutan dimensi ini berdasarkan hasil analisis ordonansi MDS 42,24 (masuk ke dalam kategori tidak/kurang) berlanjut, seperti pada Gambar 8. Dari 9 atribut pada ini hasil analisis leverage factor berdasarkan nilai RMS menunjukkan 3 atribut yang sensitif, yaitu koordinasi antar lembaga/instansi di 3 pemerintah daerah dengan BPWC $(6,41)$, ijin pembangunan KJA baru $(5,52)$ dan penegakan hukum $(4,72)$ seperti pada Gambar 9. 


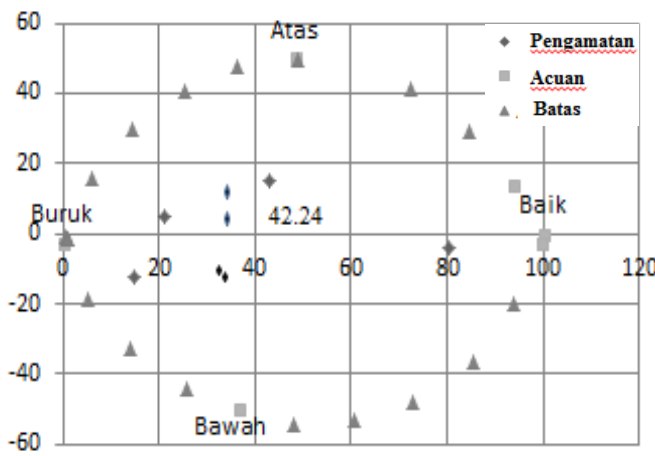

Gambar 8. Indeks keberlanjutan dimensi peraturan dan kelembagaan.

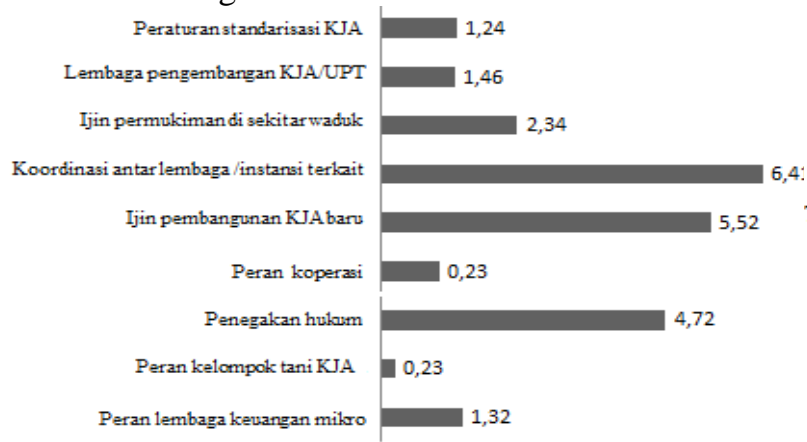

Gambar 9. Peran masing-masing atribut dimensi peraturan dan kelembagaan yang dinyatakan dalam bentuk perubahan RMS.

Secara administratif luas waduk di wilayah kabupaten Cianjur 29.603.299 $\mathrm{m}^{2}$, Purwakarta (9.154.094 $\mathrm{m}^{2}$ ) dan Bandung Barat (27.556.890 $\mathrm{m}^{2}$ ). Ketiga pemerintah daerah tersebut memiliki kepentingan dan prioritas yang belum tentu sama terhadap keberadaan waduk cirata dalam ekonomi, sosial dan lingkungan. Untuk meningkatkan nilai indeks keberlanjutan pada dimensi ini maka koordinasi ketiga pemerintah daerah dan pengelolan waduk yaitu (BPWC) menjadi sangat penting terutama dalam masalah penataan KJA dan perijinan untuk pembangunan KJA baru.

\section{Nilai Indeks Keberlanjutan Dimensi Infrastruktur dan Teknologi}

Nilai indeks keberlanjutan dimensi insfrastruktur dan teknologi berdasarkan hasil analisis MDS 68,64 masuk dalam kategori cukup berlanjut seperti pada Gambar 10. Dari 6 atribut pada dimensi ini berdasarkan nilai RMS hasil analisis leverage factor menunjukkan 3 atribut yang berpengaruh, yaitu teknologi pengendalian pencemaran air $(5,82)$, teknologi untuk deteksi upwelling $(5,52)$ dan dukungan lembaga riset untuk pengembangan KJA (4,77), seperti Gambar 11.

Mekanisme, prosedur dan persyaratan perijinan harus sama di 3 wilayah tersebut. Oleh karena itu perlu dibuat peraturan bersama yang mengatur sistem perijinan, dan pengelolaan KJA

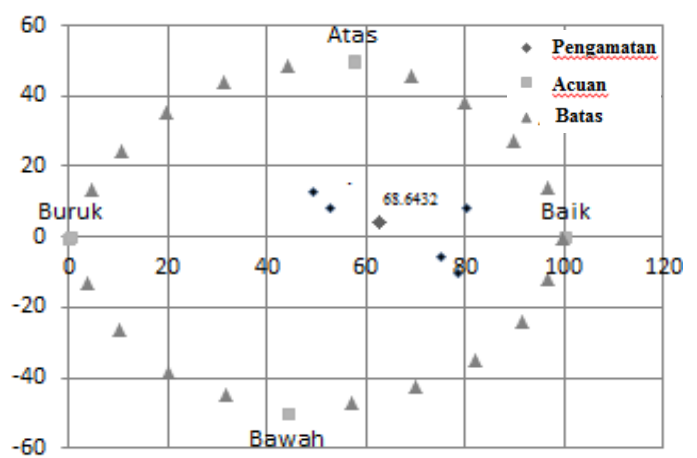

Gambar 10. Indek keberlanjutan dimensi infrastruktur dan teknologi.

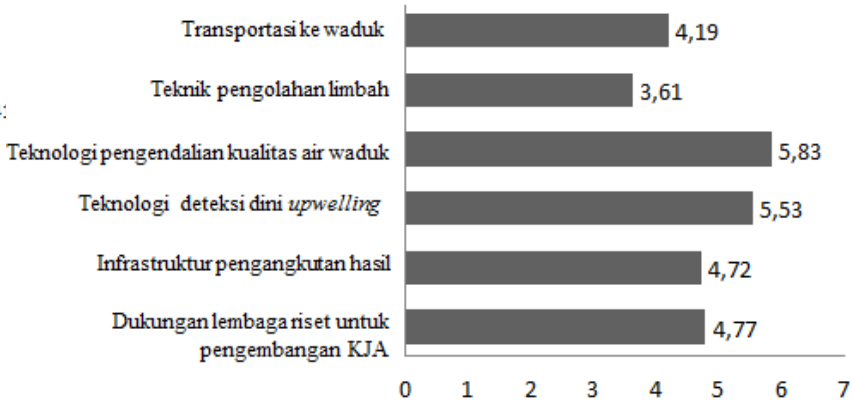

Gambar 11. Peran masing-masing atribut dimensi infrastruktur dan teknologi yang dinyatakan dalam bentuk RMS

di dalam waduk, serta penanganan limbah domestik dan limbah industri dari hulu. Hal ini juga untuk menghindari konflik horizontal antar petani KJA yang berasal dari daerah yang berbeda di kemudian hari.

Untuk meningkatkan nilai keberlajutan pada dimensi ini maka ketiga atribut ini harus diperhatikan. Teknologi pengendalian pencemaran saat ini masih belum ada, hanya dilakukan secara rutin dengan cara sampling, oleh karena itu perlu menggunakan teknologi yang canggih untuk pendekteksian parameter pencemar (BOD, COD, DO dan $\mathrm{pH}$ ). Demikian juga teknologi deteksi upwelling, sebagian besar petani hanya mengandalkan perubahan warna air dan perilaku ikan ketika akan terjadi upwelling, untuk memberikan dukungan terhadap pengembangan sistem KJA perlu dibangun kerjasama dengan lembaga riset seperti BPPT atau perguruan tinggi.

Secara keseluruhan berdasarkan hasil analisis MDS terhadap 5 dimensi keberlanjutan Waduk Cirata, nilai indek keberlanjutan masing-masing dimensi seperti pada Tabel 2. Atribut yang sensitif setiap dimensi berdasarkan hasil analisis leverage factor dengan mengacu pada nilai RMS, seperti pada Tabel 3

Nilai stress dan nilai koefisien determinasi $\left(\mathrm{R}^{2}\right)$ dari masing-masing dimensi berdasarkan hasil analisis MDS seperti pada Tabel 4. Berdasarkan 
Tabel 2. Nilai indeks keberlanjutan dimensi ekologi dan tataruang, ekonomi, sosial dan budaya, peraturan dan kelembagaan, dan infrastruktur dan teknologi.

\begin{tabular}{lcl}
\hline Dimensi & Nilai indeks keberlanjutan & Keterangan \\
\hline Ekologi dan tataruang & 45,76 & Kurang \\
Ekonomi & 63,12 & Cukup \\
Sosial dan budaya & 64,42 & Cukup \\
Peraturan dan kelembagaan & 42,24 & Kurang \\
Infrastruktur dan teknologi & 68,64 & Cukup \\
\hline
\end{tabular}

Tabel 3. Atribut yang sensitif mempengaruhi indeks keberlanjutan kinerja Waduk Cirata.

\begin{tabular}{|c|c|c|c|c|}
\hline \multicolumn{5}{|c|}{ Dimensi } \\
\hline $\begin{array}{l}\text { Ekologi dan tata } \\
\text { ruang }\end{array}$ & Ekonomi & Sosial dan budaya & $\begin{array}{c}\text { Peraturan dan } \\
\text { kelembagaan }\end{array}$ & $\begin{array}{l}\text { Infrastruktur dan } \\
\text { teknologi }\end{array}$ \\
\hline $\begin{array}{l}\text { a. Laju sedimentasi } \\
\text { Jumlah KJA } \\
\text { b. Kualitas air } \\
\text { waduk }\end{array}$ & $\begin{array}{l}\text { a. Produktivitas KJA } \\
\text { b. Jumlah tenaga } \\
\text { kerja di waduk } \\
\text { c. Kematian ikan } \\
\text { masal akibat } \\
\text { upwelling }\end{array}$ & $\begin{array}{l}\text { a. Sikap tolong } \\
\text { menolong antar } \\
\text { petani KJA } \\
\text { b. Tingkat } \\
\text { pendidikan } \\
\text { formal } \\
\text { c. Kegiatan sosial } \\
\text { keagamaan }\end{array}$ & $\begin{array}{l}\text { a. Koordinasi antar } \\
\text { lembaga/ } \\
\text { instansi terkait } \\
\text { b. Ijin pemba } \\
\text { ngunan KJA } \\
\text { c. Penegakan } \\
\text { hukum }\end{array}$ & $\begin{array}{l}\text { a. Teknologi deteksi } \\
\text { pencemaran air } \\
\text { b. Teknologi deteksi } \\
\text { upwelling } \\
\text { c. Dukungan } \\
\text { lembaga riset } \\
\text { untuk } \\
\text { pengembangan } \\
\text { KJA }\end{array}$ \\
\hline
\end{tabular}

Tabel 4. Nilai "Stress” dan $\mathrm{R}^{2}$ untuk seluruh dimensi (jumlah iterasi 2)*

\begin{tabular}{cccccc}
\hline Parameter & \multicolumn{5}{c}{ Dimensi } \\
\cline { 2 - 5 } & $\begin{array}{c}\text { Ekologi dan } \\
\text { tata ruang }\end{array}$ & Ekonomi & $\begin{array}{c}\text { Sosial dan } \\
\text { budaya }\end{array}$ & $\begin{array}{c}\text { Peraturan dan } \\
\text { kelembagaan }\end{array}$ & $\begin{array}{c}\text { Infrastruktur dan } \\
\text { teknologi }\end{array}$ \\
\hline Stress & 0,17 & 0,14 & 0,15 & 0,18 & 0,21 \\
$\mathrm{R}^{2}$ & 0,96 & 0.95 & 0.94 & 0,93 & 0,93 \\
\hline
\end{tabular}

*) jumlah iterasi cukup 2, karena nilai $\mathrm{R}^{2}$ sudah mendekati 1

Tabel 5. Hasil analisis Monte Carlo dan MDS kinerja Waduk Cirata dengan selang kepercayaan 95 persen.

\begin{tabular}{lccc}
\hline Dimensi & Hasil MDS & Hasil Monte Carlo & Perbedaan \\
\hline Ekologi dan tata ruang & 45,76 & 45,14 & 0,62 \\
Ekonomi & 63,12 & 62,98 & 0,14 \\
Sosial dan budaya & 64,42 & 64,13 & 0,29 \\
Peraturan dan kelembagaan & 42,24 & 41,98 & 0,26 \\
Infrastruktur dan Teknologi & 68.64 & 67.82 & 0.82 \\
\hline
\end{tabular}

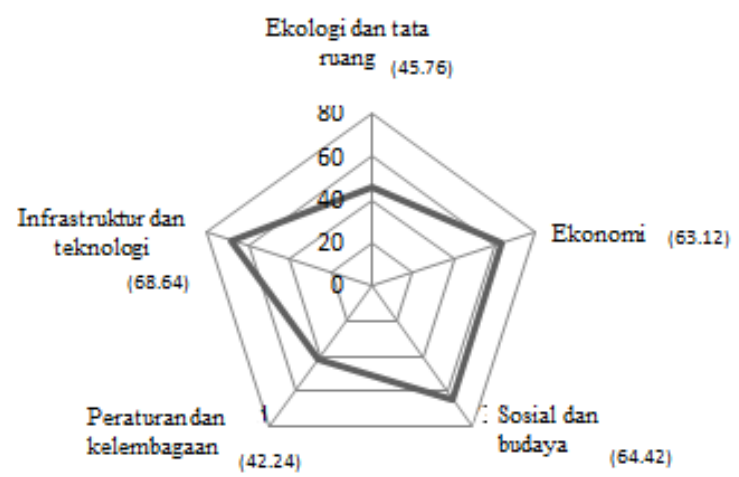

Gambar 12. Diagram layang-layang indeks keberlanjutan Waduk Cirata.

nilai stress dan $\mathrm{R}^{2}$ pada Tabel 4, maka atribut yang digunakan pada evaluasi keberlanjutan Waduk Cirata cukup baik dalam menerangkan setiap dimensi keberlanjutan yang dianalisis (nilai stress < 0,25 dan $\mathrm{R}^{2}$ sudah mendekati 1$)$.
Perbandingan hasil analisis Monte Carlo dengan MDS sangat kecil, seperti pada tabel 5. Perbedaan antara hasil analisis MDS dan Monte Carlo (Tabel 5) menunjukkan adanya kesalahan yang kecil dan memberikan perubahan pada indeks keberlanjutan dimensi yang dianalisis. Berdasarkan hasil analisis terhadap 5 dimensi tersebut, maka indeks keberlanjutan secara keseluruhan seperti pada Gambar 12.

\section{KESIMPULAN}

Berdasarkan hasil evaluasi terhadap 5 dimensi indeks keberlanjutan, perkembangan kondisi eksisting tataruang baik di hulu DAS Citarum, maupun di sekitar waduk, serta perkembangan KJA di dalam telah menyebabkan dimensi ekologi dan tata ruang, dan peraturan dan kelembagaan kurang berlanjut. Tingkat keberlanjutan kedua dimensi yang rendah ini disebabkan peningkatan 
sedimentasi akibat perubahan tata guna lahan di hulu DAS Citarum yang tidak sesuai dengan rencana tata ruangnya dan pertumbuhan KJA di luar kendali, penurunan kualitas air waduk akibat pencemaran limbah domestik dan industri, rendahnya koordinasi antar instansi, lemahnya perijinan dan masih lemahnya penegakan hukum. Untuk menjamin keberlanjutan kinerja waduk khususnya sebagai PLTA, dan tempat budidaya ikan dengan sistem KJA, serta sbagai pengendali tata air, maka BPWC perlu melakukan intervensi kebijakan khusus untuk mengendalikan perubahan tata ruang di hulu DAS Citarum dan daerah sekitar waduk, dan pengetatan perijinan untuk pembangunan KJA dan permukiman, serta pengolahan limbah di sumbernya dengan melibatkan pemerintah daerah setempat.

\section{UCAPAN TERIMAKASIH}

Kami menyampaikan terima kasih kepada pimpinan BPWC dan UPT Waduk Cirata yang telah memberikan kesempatan kepada kami melakukan penelitian selama 6 bulan.

\section{DAFTAR PUSTAKA}

Anonim, 2009. Monitoring Kualitas Air Waduk Cirata dan Perkembangan KJA 2008-2009. BPWC. Bandung.

Anonim, 2011. Laporan Tahunan Perkembangan KJA di Waduk Cirata. Unpad, Bandung.

Anonim, 2012 . Masterplan Pengembangan dan Perencanaan Waduk Cirata, PT PJB, Bandung.

Anonim, 2012 . Laporan Tahunan Kualitas Air Waduk Cirata. PT PJB, Bandung.

Anonim, 2013ª . Penentuan Indikator Pendekatan Ekosistem Dalam Pengelolaan Perikanan. Lokakarya Nasional. Bogor, 22-24 September 2013.

Anonim, 2013 . Laporan Tahunan Kualitas Air Waduk Cirata Kuartal 1. PT PJB, Bandung.

Borg, I., dan Groenen, P., 2005. Modern Multidimensional Scaling: Theory and Applications (2nd ed.). Springer-Verlag, New York. pp. 207-212.

Dahuri, R., 2004. Ocean Biodiversity, Indonesian Sustainable Development Asset. Gramedia Pustaka Utama Press, Jakarta

Dewa, R.P., 2010. Studi Potensi Upwelling di Perairan Pulau Jawa Hingga Selatan Pulau Sumbawa. Thesis. Program Pascasarjana Universitas Diponegoro, Semarang.

Fauzy, A., dan Anna, S., 2005. Permodelan Sumberdaya Perikanan dan Kelautan Untuk Analisis Kebijakan. PT Gramedia Pustaka Utama. Jakarta.
Kamal, S., dan Prajitno., 2013. Evaluasi Unjuk Kerja Turbin Air Pelton Terbuat dari Kayu dan Bambu Sebagai Pembangkit Listrik Ramah Lingkungan Untuk Pedesaan. Jurnal Manusia dan Lingkungan, 20(2):190-198.

Khanna. P., Babu, P.R., dan George, M.S., 1999. Carrying Capacity as A Basis for Sustainable Development : A Case Study of National Capital Region in India. Progess in Planning 52:101-163.

Kholil dan Dewi, I.P., 2014. The Use of MDS (Multidimensional Scaling) to Analize the Level of Sustainability Fisheries Resources Management in Thousand Island. Int. J. Marine Science, 4(27):245-255.

Kruskal, J.B., dan Wish, M., 1977. Multidimensional Scaling. Sage Publications. Beverly Hills.

Lee, M.D., 2011. Determining The Dimensionality of Multidimensional Scaling Model for Cognitive Modeling. J. Math. Psichology, 45:149-161.

Li, W., dan Liu, C., 2014. Effects of Land Use Changes on Soil Erosion in a Fast Developing Area. Int. J. Environ. Sci. \& Technol., 11(6):1549-1562.

Mawardi, 2010. Kerusakan Daerah Aliran Sungai dan Daya Dukung Sumberdaya Air di Pulau Jawa Serta Upaya Penangannya. Journal Hidrosfir Indonesia. 5(2):1-11.

Moffat, I., Hanley, N., and Wilson, M.D., 2001. Measuring and Modeling Sustainable Development. The Parthenon Publishing Group. New York.

Meadows, D.H., Randers, J., dan Meadow, D.L., 2004. Limit to Growth, The 30-year Synopsis Minnesotans for sustainability. www.context. org/ICLIB/123/Meadows.htm (diakses 20 Juni 2014).

Noordiningroom, Anna, Z., dan Suryana, A.A., 2012. Analisis Bioekonomi Model GordonSchaefer. Studi kasus Pemanfaatan Ikan Nila di Perairan Umum Waduk Cirata Kabupaten Cianjur Jawa Barat. Jurnal Perikanan dan Kelautan, 3(3):263-274.

Nurmalina, R., 2008. Analysis of Sustainability Index and Status of Rice Availability System in Several Regions in Indonesia. J. Agro Economic, 26(1):47-79.

Pitcher, T.J., dan Preikshot, D., 2001. RAPFISH : A Rapid Appraisal Technique to Evaluate the Sustainability Status of Fisheries. Fisheries Research, 49:255-270.

Respati, Y.D., 2013. Kajian Rencana Konservasi Untuk Pengendalian Sedimentasi di Waduk Cirata. Program Pascasarjana. Institut Teknologi Bandung. Bandung. 
Rees, W.E., 1996. Revisiting Carrying Capacity : Area Based Indicator of Sustainability. Population and Environment. Int. J. Interdiciliplinary Studies, 17(3):195-215.
Wackernagel, M., 1994. Ecological Foot Print and Approach Carrying Capacity : A Tool for Planning Toward Sustainability. University of British Columbia. Ottawa. 